\title{
The Reform and Prospects of Compulsory Drug Rehabilitation Programmes in China
}

\author{
Xiaozheng Lei \\ Department of Criminal Legal Science, Beijing Normal University, Beijing, China \\ Email: na.jiang@bnu.edu.cn
}

How to cite this paper: Lei, X. Z. (2019). The Reform and Prospects of Compulsory Drug Rehabilitation Programmes in China. Chinese Studies, 8, 148-155.

https://doi.org/10.4236/chnstd.2019.83012

Received: June 4, 2019

Accepted: August 25, 2019

Published: August 28, 2019

Copyright (C) 2019 by author(s) and Scientific Research Publishing Inc. This work is licensed under the Creative Commons Attribution International License (CC BY 4.0).

http://creativecommons.org/licenses/by/4.0/

\begin{abstract}
Globally, the prevalence of drugs has become a major problem. Rehabilitation and correction programmes are experiencing great difficulties. In Sichuan province of China, two comparative modes, namely "Blue Lotus Home" and "Green Return Home" have been established, and are both aiming at assisting the drug users to restore their normal families and community lives. Both of the modes help to reduce the compulsory nature of rehabilitation programmes. Our experiences show that such reforms demand multi-level contributions from a society; in addition, it is also important to give respect to basic human rights and to provide professional services accordingly. Further contributions are required in terms of legal aid and psychological counselling to drug users.
\end{abstract}

\section{Keywords}

Reducing Compulsory Elements, Drug Control, Relapse Rate, Humane Care

\section{Introduction}

At present, the work of drug prevention is experiencing severe difficulties in China. One of the great challenges faced is the high relapse rate. Recurrence is a very difficult problem in drug treatment, and recurrence rate among heroin addicts is extremely high. A survey of 439 heroin addicts in compulsory isolation drug treatment centres in Guangxi, Fujian, and Hainan provinces showed that the proportion of relapse within 30 days after drug treatment was 75.3 , and the annual relapse rate was 80.0 (Gu, Zhang, Zhang, Deng, \& Wu, 2018). At present, China pays more and more attention to community drug treatment and community rehabilitation. However, there are still some factors that lead to a high rate of relapse, such as shortage of drug rehabilitation funds, shortage of drug rehabilitation personnel, and shortage of coordinated management mechanisms. 
In addition, compulsory isolation and drug treatment and community discipline can not be well coordinated, making it difficult to carry out effective work. Article 31, paragraph 2, of the Anti-Drug Law stipulates that drug addicts should be treated for their drug addiction; Articles 33 to 48 respectively stipulates conditions and procedures for voluntary drug rehabilitation, community drug rehabilitation, treatments and compulsory detentions. In March 2012, twelve international organisations, including the International Labour Organization, the Office of the High Commissioner for Human Rights, World Health Organization and UNAIDS, launched a joint statement together, calling for the closure of compulsory drug detention and rehabilitation centres, to provide treatments. Compulsory detention raises concerns on human rights issues as it may threaten the health of detainees, such as an increased susceptibility of detainees to contract HIV and tuberculosis infections. This statement played an important role in promoting the reform of China's drug rehabilitation centres and so to promote human rights protection. After the abolition of the labour education system in 2013, China's drug rehabilitation work has made significant progress in terms of reducing the involvement of police and compulsory detentions. Of course, the management of repeat drug users is still a challenging issue.

In China, various factors such as the disparate development processes and inadequate supports in different regions still play an role in the retaining of compulsory treatment. This is especially the case for those repeat drug users and those who are infected with HIV after drug use. Many studies have pointed out that the current compulsory isolation and detoxification model still has various disadvantages, including a lack of balance between treatment and punishment (Wang, 2015). Meanwhile, many compulsory rehabilitation centres have explored alternative methods. The drug rehabilitation programme in Sichuan has adopted two models to reduce the compulsory elements, called "The Blue Lotus Home" and "The Green Return Home" respectively. Both have been evaluated as bringing positive results. Therefore, the Beijing Normal University research group paid its second visit to gather experience and to establish a theoretical foundation for such approaches.

\section{Reform and Effect of "Blue Lotus Home" Model}

Traditional compulsory treatments entail characteristics such as compulsory labour, compulsory corrections and the involvement of police authorities (Zhang, Li, \& Qian, 2011). These compulsory detention factors assume that individuals are exposed to the potential of HIV infections. Comparatively at Ziyang city, the "Blue Lotus Home" model sets up a courtyard style home and invites social involvement including psychological counselling and medical supports, to break the high wall barriers associated with conventional compulsory centres. "Blue Lotus" is a kind of special lotus, whose leaves and flowers float above the water, is regarded as a symbol of reincarnation, resurrection and reproduction. In ancient Egypt, "Blue Lotus" was believed to have the medical value of immortality. At the moment, "Blue Lotus" is believed to express its respect to all people, show- 
ing care for lives (Lei, Lin, Zhao et al., 2014).

What is the effect of this model? The research team verified the positive effects of this model via various data analyses, including a study of the rate of disciplinary violations, rates of the occurrence of particular categories of accidents, and infection rates. There was a low tendency for the involvement of the project personnel to undertake disciplinary sanctions, which is about $30 \%$ lower than the comparative models; and no staff member contracted infections with HIV due to their exposure, even though "Blue Lotus Home" has received more than 2500 HIV-infected patients; and there has been no occurrence of major accidents, in terms of accidental death, accidental flees, accidental security issues, drug usage inside the centres or a major outbreak of infections. With more than 160 people returned to the society, no one has maliciously transmitted HIV to others.

\section{1) Material supports}

Material support is a key factor in the operation of the current programme. Following the traditional compulsory isolation mode, there is an imbalance between economic and cultural developments in various places. The material support of "Blue Lotus Home" is mainly reflected in the construction of courtyard homes, which are unique in the style of western Sichuan. Various centres are established including the police training centre, the medical care centre, the psychological correction centre, the cultural and sports centre, the physical rehabilitation centre, the art centre and cafes.

Importantly the "Blue Lotus Home" represents an atmosphere of "home" and expresses sufficient care and respects to drug users. How does it work? Compared with the traditional labour education system, it shows more respect to privacy and individuality, which means each individual has his or her own bed and each room constitutes a family unit with their characters fully recognized."Home" provides basic respect for privacy and individual space.

\section{2) Professional services}

In the compulsory isolation drug rehabilitation centre, the police image dominates, which is hard to avoid in many alternative rehabilitation programmes. "Blue Lotus Home" dilutes the police image and their involvements but instead focuses on professional counselling services. The central issue is that, at the beginning of the programme, each participant chooses their own counsellor. The counsellor will then consider the different physical, psychological and personality issues, and then guide these individuals to review their own problems objectively, so helping them to adjust accordingly.

Detoxification counsellors will summarize their work daily, in particular, to record the problems and solutions proposed by the members of the home, and follow up on their practices. It can be said that these counsellors play quite a different role from that of the police, and show more sincere respect and care. This helps to establish a healthy friendship and further reduce the risk of emotional reactions and dangerous behaviour, including resistance.

\section{3) Medical treatments}


Many drug addicts experience both psychosocial and behavioural disorders, which exist on top of their neuropsychiatric disorders. The so-called detoxification involves thirty percent medical treatment and seventy percent counselling therapies. The "Blue Lotus Home" is characterized by its provision of periodic medical services: the initial period of 1 to 2 months is associated with primary evaluations and check-ups; the improvement period at 18 - 19 months is associated with regular clinical meetings; and the third phase which is no more than 3 months, which involves methadone maintenance treatment; regular doctor visits will be provided to ensure continuing treatment compliance.

\section{4) Social participations}

In the traditional compulsory isolation and detoxification model, authorities worry about the occurrence of accidents and privacy issues, and so social organizations and volunteers are not part of the specific processes. "Blue Lotus Home" adopts a people-centred working method and invites social forces to contribute, including doctors, parents and volunteers. This is a distinguishing characteristic.

One of its experiences is having detainees interact with their families. Repairing family life damage is the key to the construction of psychological order. It is very difficult for people who have left the family to take care of themselves. Here, not only the family members of individuals in the centres are invited but also field experts and scholars are invited to teach and counsel individuals on various issues.

Another valuable experience is that it promotes Volunteer supports. Specifically, it includes the local party members and legal aid workers to provide social support. These people also help to conquer challenges arising from health, family, and employment issues. The aim is to use all possible social resources that can be mobilized to engage in the education of different families. This includes involving different entities, including Beijing Normal University and Mianyang Normal University, and other different charity organizations from Yunnan, Shanghai and Hong Kong.

\section{Integration with Community Service: "Green Return Home" Model}

Although the "Blue Lotus Home" diluted some of the compulsory aspects, it still operates within a prison like environment, and there are still obstacles to get programme participants to get back into their communities. The Xinhua Compulsory Drug Rehabilitation Centre, in Sichuan, explores a "Green Home" model, adopting a concept of "coming from society and returning back to society". It breaks the enclosed boundaries between the drug rehabilitation centre and the society, and the individual families. It provides occupational training, job seeking and anti-drug education. What is this green return? It targets drug users for voluntary positions, and their relatives will have to guarantee their participation, and with further approvals they may enter into the programmes. All drug users then are called "residents", and they will mainly be engaged in gar- 
dening, landscaping, and any other botanical work in the centre. It is important to recognize that all these residents will be treated like company employees and be receiving equal pay and at fair rates.

How to evaluate the efficacy of such programmes? Many studies have pointed out that the relapse rate of those participating in conventional compulsory programmes is above $85 \%$. For example, data from the National Centre for Drug Abuse Detection of 2008 showed that reusing heroin within 30 days of drug treatment (Compulsory isolation and detoxification) accounted for 51.6 percent. After some addicts received one-year drug treatment, the recurrence rate was still 88.2\% (Zhang, Fang, Tang et al., 2013). An independent study was carried out on the Green Home participants. This study involved individual interview, telephone interview, and social interview. The latest research which targeted 77 participants shows that 70 persons show no sign of relapse, which means $90.9 \%$ of the mare clean, and their overall employment rate is $88.3 \%$. The selection of 77 participants is anonymous. After setting a time point, researchers randomly selected participants based on their serial numbers in the center. Interviewers communicated with interviewees directly in their residential places. Telephone interview was applied to participants who didn't have residential places. To verify the information, interviewers visited family members of 77 participants, or police stations, village committees.

In the interview investigation, there are several successful cases. Wang, one of the respondents, he went back to Ya'an city after his successful drug treatment. He opened a tea factory, learned tea culture, and combined production and sales. Not only did he make his own money, but he also took villagers to become rich. Mr Jiang became a fire fighter. Mr Xiao worked in Xi'an oil front. Mr Liang worked as a construction designer on a construction site. There are also unsuccessful cases, for example, Mr Guo was released in August 2014, but he soon got addicted to drugs again.

So, it is working very well. The question is how?

\section{1) The green issue}

There are no compulsory elements. There are no high walls barricading people from the outside world and all drug users are free to leave and keep in touch with their families at anytime. It does not mean it gives any less weight to education or correction issues. It delivers educational programmes and counselling programmes, and it still evaluates performances. The main theme is focusing on taking care of the human needs of individuals, and the family courtyard living environment is expected to help these participants to get back to a proper community life. There are special rooms which satisfy the needs of the families for visits and overnight stays. Participants are also mainly self-managed, which may help to strengthen their capacities to reject drug use in the future. The Green Return Home plans to set up more family-living areas, which may accommodate 6000 people at the same time and it ensures that homeless drug users can settle in as well.

2) Employment issue 
Article 52 of the Narcotic Control Act stipulates that drug users should not be discriminated in terms of enrolment for education, to be employed or seeking social security. Relevant departments, organizations and personnel shall provide necessary guidance and assistance to them. Many domestic and international researches have pointed out that drug users are still vulnerable to all sorts of discrimination, because it is hard to gain employment and this may cause a high relapse rate. That is to say, most of the drug users lack employable skills and it is hard for them to return to society. Some of these problems have been solved under the Green Return Home Programme.

Additionally, besides the participants of "Green Return Home", all drug users coming out of any compulsory rehabilitation centres in Mianyang gare offered employment opportunities. Overall, there are 3000 job vacancies offered in a range of fields, including modern agricultural work, gardening work, hotel services, electronic manufacturing work and so on. Equipped with various skills from their time in the rehabilitation centres, any participant may find opportunities of employment once contracts are signed with individual enterprises.

\section{3) The education issue}

In our society people are scared of drugs and because of this, they tend to discard drug users and tag them as drug addicts. With the development of social education in the general society, this kind of view is being challenged. In particular, the Green Return Home programmes are meant to challenge such views further.

Green Return Home invites different social groups to visit their sites and provide lectures to enable them to have a profound understanding of the drug issue. One issue raised is that there are both social and individual factors playing a role in driving these individuals to drugs. Drug users are vulnerable groups who deserve tolerance and care. Of course, not everyone agrees with such a theme of education. Some concerns have been raised about the security issues at relevant programmes, and how these programmes may continue after any outbreak of accidents.

\section{Prospects of the Reform}

The problem of drug control is not a simple, unified social problem, so it should involve diversified solutions. These two sample models might be useful for other parts of the country and sample studies could be provided to the international communities. If these two models are promoted, they would greatly improve the level of human rights protection and the ability to return to society of the anti-drug correction system in China. These models are more suitable for China than the proposal to abolish the correctional institutions.

\section{1) The engagement of multi-resources led reforms}

From re-education through labour to compulsory rehabilitation centres, it means a major forward step been taken. The current experience shows that there are reforms to be taken at multiple levels via the use of multiple resources. 
Both of the models show a common theme, which is even within the compulsory centres, there should be less focus on compulsory elements and a greater emphasis on creating a social relaxing environment. Regarding the education and correction of drug users, there is a need for multiple engagements from different parties, especially social and governmental engagements, and a focus on collaboration work.

2) Human rights protections and the involvement of professional services

Drug users are law violators, but also victims and patients (Wang, 2015). To reduce any compulsory elements in any rehabilitation program, the essence is to provide humane care. By providing humane care, one should focus on the protection of human rights and to provide good quality of professional services. This research supports any form of rehabilitation centre, as long as their focus is on delivering care and sincere concern to participants. Otherwise, experiments may not succeed.

\section{3) Participation of various social groups}

According to the conflict theory, drug users must be facing lots of internal entanglements and external disputes themselves. The settlement of their disputes is only possible with the help of multiple players. It may not be correct just to talk about the laws of individual countries or only to talk about any single form of social customs (Zhao, 2003). The central issue is to develop rehabilitation centres to further implement the concept of "big society, small government". Overall all, we must dare to have the involvement of different domestic and international social groups in a legitimate manner. For various reasons drug users and HIV-positive personnel may have faced difficult situations due to domestic, personal or health crisis, which make them vulnerable. Accordingly, different social groups should be invited and help to sort these problems out. However, it might be hard to coordinate different groups for collaborative work. It might be important for the involvement of government to pay for such services and to promote social donations as well. Individual coordinators or centre staff should also to keep themselves updated with their knowledge in terms of providing appropriate legal aid and psychological counselling to drug users.

\section{Conclusion}

Both of the two models discussed here namely the "Blue Lotus Home" and "Green Return Home" operated in Sichuan province, show exactly how they have diluted the compulsory aspect of their programmes. It is hard for the conventional rehabilitation centres to focus purely on the control of drug users anymore. Also, it is hard for the government to act on its own without the participation of other social groups. Both the two models discussed establish a trend, which shows it is necessary to get the involvement of social groups. Of course, the development of any drug rehabilitation correction model still demands the engagements of local party and governmental bodies to control risks, so as to bring about the best outcomes. 


\section{Contribution}

Graduate student Yan Shuyue (1994), Yao Xiaofu (1993) Chen Qian (1992) also contributed to the data collection of this article.

\section{Conflicts of Interest}

The author declares no conflicts of interest regarding the publication of this paper.

\section{References}

Gu, Y., Zhang, R. M., Zhang, C. B., Deng, Y., \& Wu, T. H. (2018). Comparative Analysis on Relapse Rates of 439 Heroin Addicts in Guangxi, Fujian and Hainan. Chinese Journal of Drug Dependence, 4, 288-290.

Lei, X. Z., Lin, M. C., Zhao, Z. Y. et al. (2014). Protect the Blue Lotus: Humanistic Care and Legal Guarantee for AIDS Management in China. Beijing: Law Press.

Wang, R. S. (2015). On the Perfection of the System of Compulsory Drug Rehabilitation in China. Journal of East China Normal University (Humanities and Social Sciences), 3, 57-62.

Zhang, X., Fang, Z. X., \& Tang, X. et al. (2013). Discussion on Quality Control Model of Comprehensive Community Intervention for Relapse Prevention. Chinese Journal of Drug Dependence, 4, 296-299.

Zhang, Y., Li, Y., \& Qian, Z. H. (2011). Study on Centralized Management Model of AIDS Infected Persons in Supervision Places of Police Authorities in China. Social Sciences Journal of Universities in Shanxi, 2, 76-84.

Zhao, X. D. (2003). Power and Justice: Dispute Resolution and Pluralistic Authorities in Rural Society. Tianjin: Tianjin Classics Publishing House. 